\title{
Longitudinal analysis of the vaginal microflora in pregnancy suggests that $L$. crispatus promotes the stability of the normal vaginal microflora and that $L$. gasseri and/or $L$. iners are more conducive to the occurrence of abnormal vaginal microflora
}

\author{
Hans Verstraelen* ${ }^{* 1}$, Rita Verhelst ${ }^{\dagger 2}$, Geert Claeys ${ }^{3}$, Ellen De Backer ${ }^{2}$, \\ Marleen Temmerman ${ }^{1}$ and Mario Vaneechoutte ${ }^{2}$
}

\begin{abstract}
Address: ${ }^{1}$ Department of Obstetrics \& Gynaecology, Faculty of Medicine and Health Sciences, Ghent University, Ghent, Belgium, ${ }^{2}$ Laboratory Bacteriology Research, Department of Clinical Chemistry, Microbiology and Immunology, Faculty of Medicine and Health Sciences, Ghent University, Ghent, Belgium and ${ }^{3}$ Department of Clinical Chemistry, Microbiology, and Immunology, Faculty of Medicine and Health Sciences, Ghent University, Ghent, Belgium

Email: Hans Verstraelen* - hans.verstraelen@ugent.be; Rita Verhelst - rita.verhelst@ugent.be; Geert Claeys - geert.claeys@ugent.be; Ellen De Backer - ellekendb@yahoo.com; Marleen Temmerman - marleen.temmerman@ugent.be; Mario Vaneechoutte - mario.vaneechoutte@ugent.be * Corresponding author †Equal contributors
\end{abstract}

Published: 2 June 2009

BMC Microbiology 2009, 9:1 I6 doi:10.1 I86/147I-2180-9-116

This article is available from: http://www.biomedcentral.com//47/-2180/9/II6

(C) 2009 Verstraelen et al; licensee BioMed Central Ltd.

This is an Open Access article distributed under the terms of the Creative Commons Attribution License (http://creativecommons.org/licenses/by/2.0), which permits unrestricted use, distribution, and reproduction in any medium, provided the original work is properly cited.

\begin{abstract}
Background: Despite their antimicrobial potential, vaginal lactobacilli often fail to retain dominance, resulting in overgrowth of the vagina by other bacteria, as observed with bacterial vaginosis. It remains elusive however to what extent interindividual differences in vaginal Lactobacillus community composition determine the stability of this microflora. In a prospective cohort of pregnant women we studied the stability of the normal vaginal microflora (assessed on Gram stain) as a function of the presence of the vaginal Lactobacillus index species (determined through culture and molecular analysis with tRFLP).
\end{abstract}

Results: From 100 consecutive Caucasian women vaginal swabs were obtained at mean gestational ages of 8.6 (SD I.4), 2 I.2 (SD I.3), and 32.4 (SD I.7) weeks, respectively. Based on Gram stain, 77 women had normal or Lactobacillus-dominated vaginal microflora (VMF) during the first trimester, of which 18 had grade la (L. crispatus cell morphotypes) VMF (23.4\%), I6 grade lab (L. crispatus and other Lactobacillus cell morphotypes) VMF (20.8\%), and 43 grade lb (non-L. crispatus cell morphotypes) VMF (55.8\%). Thirteen women with normal VMF at baseline, converted in the second or third trimester $(16.9 \%)$ to abnormal VMF defined as VMF dominated by nonLactobacillus bacteria. Compared to grade la and grade lab VMF, grade lb VMF were 10 times (RR $=9.49,95 \% \mathrm{Cl}$ $1.30-69.40)$ more likely to convert from normal to abnormal VMF $(p=0.009)$. This was explained by the observation that normal VMF comprising $L$. gasseriliners incurred a ten-fold increased risk of conversion to abnormal VMF relative to non-L. gasseriliners VMF (RR I0.4I, 95\% Cl I.39-78.I2, $\mathrm{p}=0.008$ ), whereas normal VMF comprising $L$. crispatus had a five-fold decreased risk of conversion to abnormal VMF relative to non-L. crispatus VMF (RR 0.20, 95\% Cl 0.05-0.89, $p=0.04$ ).

Conclusion: The presence of different Lactobacillus species with the normal vaginal microflora is a major determinant to the stability of this microflora in pregnancy: $L$. crispatus promotes the stability of the normal vaginal microflora while $L$. gasseri and/or $L$. iners predispose to some extent to the occurrence of abnormal vaginal microflora. 


\section{Background}

Under normal conditions, the lower female genital tract harbours a mutualistic microflora that primarily consists of lactobacilli which confer antimicrobial protection to the vagina as a critical port of entry for local, ascending and systemic infectious disease $[1,2]$. The lactobacillidriven defence of the vaginal niche is in its essence seized as a principle of colonisation resistance, i.e. the vaginal lactobacilli prevent colonisation of the vaginal epithelium by other microorganisms, through a variety of mechanisms [3].

Despite their intrinsic antimicrobial potential however, vaginal lactobacilli fail to retain dominance in a considerable number of women, resulting in overgrowth of the vaginal epithelium by other bacteria, as observed, most typically, with anaerobic polymicrobial overgrowth in bacterial vaginosis [1], or less commonly, with overgrowth by streptococci, including group A [4] and group B streptococci $[5,6]$, by bifidobacteria $[7,8]$, or by coliforms such as E. coli $[5,6,9]$.

Loss of the indigenous lactobacilli strongly predisposes to ascending genital tract infection, which in pregnancy is a major cause of chorioamnionitis, amniotic fluid infection, and preterm birth $[1,2]$. A depletion of the vaginal Lactobacillus microflora further predisposes to the acquisition of sexually transmitted infectious diseases such as gonorrhoea [10,11], chlamydiosis [11], and HIV infection $[12,13]$.

The mechanisms involved in the loss of the mutualistic lactobacilli remain largely unknown and hence it remains elusive whether lactobacilli for some reason are losing ground thereby allowing other microorganisms to proliferate or whether other bacteria for some reason elicit overgrowth thereby displacing the resident lactobacilli. In fact, the ecological conditions of the vaginal niche, like the low $\mathrm{pH}$, which enable lactobacilli to inhibit overgrowth by other microorganisms, are intermittently disturbed by non-microbial factors, primarily by the menses [14] and by sexual intercourse [15], to which some practices like vaginal douching [16] may add further disturbance.

It has not been extensively investigated however to what extent interindividual differences in vaginal Lactobacillus community composition determine the stability of this microflora neither how differences in host innate immunity contribute to interindividual differences in susceptibility to bacterial overgrowth of the vagina. The normal vaginal microflora has recently been found to consist primarily of one or more of merely four distinct species, in particular $L$. crispatus, $L$. jensenii, $L$. gasseri and $L$. iners $[7,17,18]$. Here, we established the stability of the vaginal microflora during pregnancy as a function of the presence of each of these index species, in a prospective cohort study.

\section{Results}

From 100 consecutive Caucasian women vaginal swabs for Gram stain-based microscopy, tRFLP, and culture were obtained at mean gestational ages of 8.6 (SD 1.4), 21.2 (SD 1.3), and 32.4 (SD 1.7) weeks, respectively.

\section{Vaginal microflora status according to Gram stain at baseline and on follow-up}

Based on Gram stain, 77 women presented with normal or grade I vaginal microflora (VMF) during the first trimester, of which 18 had grade Ia (primarily L. crispatus cell morphotypes) VMF (23.4\%), 16 grade Iab (L. crispatus and other Lactobacillus cell morphotypes) VMF (20.8\%), and 43 grade Ib (primarily non-L. crispatus cell morphotypes) VMF (55.8\%). Of these, 64 women $(83.1 \%)$ maintained grade I VMF throughout pregnancy, whereas 13 women with grade I VMF during the first trimester, converted to abnormal VMF in the second or third trimester $(16.9 \%)$ (Table 1). Conversely, of the 23 women with abnormal VMF in the first trimester (grade I-like (5), grade II (11), grade III (4), and grade IV (3)), 13 reconverted to normal VMF $(56.5 \%)$ in the second or third trimester (Table 2).

Among the 13 women with grade I VMF during the first trimester and who converted in the second or third trimester to abnormal VMF (Table 1), the transition involved once a transition from grade Ia VMF to abnormal VMF (grade I-like) $(1 / 18$ or $5.6 \%)$, twelve times a transition from grade Ib VMF to abnormal VMF (grade I-like (4), grade II (7), and grade III (1)) (12/43 or $27.9 \%)$, while none of the 16 women with grade Iab VMF converted to abnormal VMF (Table 1). Accordingly, compared to grade Ia and grade Iab VMF, grade Ib VMF were about 10 times $(\mathrm{RR}=9.49,95 \%$ CI $1.30-69.40)$ more likely to convert from normal to abnormal VMF ( $\mathrm{p}=0.009$ ).

\section{Prevalence of Lactobacillus species according to tRFLP and culture at baseline and on follow-up}

We further elaborated on the above findings through the study of the prevalence over time of the distinct Lactobacillus species as determined through tRFLP and culture. Through tRFLP and culture, the vaginal lactobacilli comprising the grade I VMF were identified to be predominantly one or more of four different Lactobacillus species, i.e., L. crispatus, L. jensenii, L. gasseri and L. iners (Table 3). As the latter two species could not be differentiated from each other on TRFLP analysis and since both species could not be cultured in 9 cases, their presence is further referred to as L. gasseri/L. iners. 
Table I: Overview of microflora patterns for patients who displayed a conversion from normal to abnormal microflora $(n=$ 13)

Microflora grade on Gram stain

\begin{tabular}{|c|c|c|c|}
\hline patient number & trimester I & trimester II & trimester III \\
\hline PB2003/003 & $\mathrm{lb}$ & I-like & I-like \\
\hline PB2003/007 & $\mathrm{lb}$ & III & la \\
\hline PB2003/0/3 & $\mathrm{lb}$ & II & $\mathrm{lb}$ \\
\hline PB2003/0/8 & la & la & I-like \\
\hline PB2003/019 & $\mathrm{lb}$ & II & II \\
\hline PB2003/049 & $\mathrm{lb}$ & $\mathrm{lb}$ & II \\
\hline PB2003/084 & $\mathrm{lb}$ & II & la \\
\hline PB2003/10I & lab & $\mathrm{lb}$ & II \\
\hline PB2003//I6 & $\mathrm{lb}$ & I-like & II \\
\hline PB2003//30 & $\mathrm{lb}$ & I-like & $\mathrm{lb}$ \\
\hline PB2003// 47 & $\mathrm{lb}$ & $\mathrm{lb}$ & I-like \\
\hline PB2003// 48 & $\mathrm{lb}$ & $\mathrm{lb}$ & II \\
\hline PB2003//55 & $\mathrm{lb}$ & $\mathrm{lb}$ & ॥ \\
\hline
\end{tabular}

Gram stained vaginal smears were scored according to the criteria previously described by Verhelst et al [7]. Briefly, Gram-stained vaginal smears were categorized as grade I (normal) when only Lactobacillus cell types were present, as grade II (intermediate) when both Lactobacillus and bacterial vaginosis-associated cell types were present, as grade III (bacterial vaginosis) when bacterial vaginosisassociated cell types were abundant in the absence of lactobacilli, as grade IV when only gram-positive cocci were observed, and as grade I-like when irregularly shaped or curved gram-positive rods were predominant [7]. For the purpose of this study, grade I or Lactobacillus-dominated vaginal microflora is designated as 'normal vaginal microflora' and all other grades as 'abnormal vaginal microflora'.

L. crispatus, L. jensenii, and L. gasseri/iners were present with 39,20 , and 43 women in the first trimester respectively. When accounting for the entire follow-up period, L. crispatus persisted at a rate of $92.3 \%$, L. jensenii at a rate of $80.0 \%$ and L. gasseri/iners at a rate $69.8 \%$ (Table 4 ).

We subsequently accounted for changes in the prevalence of Lactobacillus index species by accounting for the first-tosecond and second-to-third trimester transitions respectively.
Table 2: Overview of microflora patterns on Gram stain on follow-up for patients who displayed an abnormal microflora in the first trimester $(n=23)$

\begin{tabular}{|c|c|c|c|}
\hline patient number & trimester I & trimester II & trimester III \\
\hline PB2003/070 & I-like & $\mathrm{lb}$ & la \\
\hline PB2003//06 & I-like & lb & $\mathrm{lb}$ \\
\hline PB2003// 20 & I-like & III & la \\
\hline PB2003/I/ 7 & I-like & I-like & I-like \\
\hline PB2003/088 & I-like & I-like & IV \\
\hline PB2003/I II & II & la & la \\
\hline PB2003// 23 & II & lab & la \\
\hline PB2003/0/2 & II & $\mathrm{lb}$ & $\mathrm{lb}$ \\
\hline PB2003// 08 & II & I-like & la \\
\hline PB2003/063 & II & I-like & I-like \\
\hline PB2003/076 & II & II & $\mathrm{lb}$ \\
\hline PB2003/0I 7 & II & III & $\mathrm{lb}$ \\
\hline PB2003/080 & II & I-like & IV \\
\hline PB2003/044 & II & II & I-like \\
\hline PB2003/046 & II & II & II \\
\hline PB2003// 05 & II & II & II \\
\hline PB2003/078 & III & lb & $\mathrm{lb}$ \\
\hline PB2003/079 & III & lb & $\mathrm{lb}$ \\
\hline PB2003/094 & III & I-like & la \\
\hline$P B 2003 / / 32$ & III & III & III \\
\hline PB2003// 44 & IV & I-like & $\mathrm{lb}$ \\
\hline PB2003/025 & IV & I-like & I-like \\
\hline PB2003/008 & IV & IV & IV \\
\hline
\end{tabular}

Gram stained vaginal smears were scored according to the criteria previously described by Verhelst et al [7]. Briefly, Gram-stained vaginal smears were categorized as grade I (normal) when only Lactobacillus cell types were present, as grade II (intermediate) when both Lactobacillus and bacterial vaginosis-associated cell types were present, as grade III (bacterial vaginosis) when bacterial vaginosis-associated cell types were abundant in the absence of lactobacilli, as grade IV when only gram-positive cocci were observed, and as grade l-like when irregularly shaped or curved grampositive rods were predominant [7]. For the purpose of this study, grade I or Lactobacillus-dominated vaginal microflora is designated as 'normal vaginal microflora' and all other grades as 'abnormal vaginal microflora'. 
L. crispatus was present in 39 respectively 44 women with grade I VMF during the first respectively second trimester. When accounting for the first-to-second and second-tothird trimester transitions respectively, L. crispatus disappeared twice $(5.1 \%)$ respectively once $(2.3 \%)$. So, overall, L. crispatus as a member of the normal VMF $(\mathrm{n}=83)$ persisted in the vast majority of cases $(96.4 \%)$ throughout the following trimester.

L. jensenii in turn was present in 20 respectively 22 women with grade I VMF during the first respectively second trimester. When accounting for the first-to-second and second-to-third trimester conversions respectively, L. jensenii disappeared on two (10.0\%) respectively five occasions $(22.7 \%)$. So, overall, L. jensenii occurring with normal VMF $(\mathrm{n}=42)$, sustained throughout a subsequent trimester at a rate of $83.3 \%$. Hence, $L$. jensenii was found to be a significantly less stable microflora component as compared to L. crispatus, with the likelihood of L. jensenii disappearing equalling a McNemar odds ratio of 11.67 (95\% CI $3.45-47.51, \mathrm{p}<0.001)$.

L. gasseri and/or L. iners - designated L. gasseri/iners - were present in 43 respectively 40 women with grade I VMF during the first respectively second trimester. When accounting for the first-to-second and second-to-third trimester conversions, L. gasseri/iners got lost on seven (16.3\%) respectively six occasions (15.0\%). Accordingly, L. gasseri/iners as members of the normal VMF $(n=83)$ continued to be present in a following trimester at a rate of $84.3 \%$. Hence, compared to L. crispatus, L. gasseri and/ or iners were found to be significantly less stable microflora components (McNemar odds ratio 23.33, 95\% CI $7.10-92.69, \mathrm{p}<0.001)$.

\section{Association between the presence of distinct Lactobacillus species at baseline and vaginal microflora status on follow- up}

We explored whether the observations on the stability of the grade I VMF as determined by Gram stain correlated with the observations on the stability of the distinct Lactobacillus species observed with grade I VMF as determined through tRFLP and culture.

Normal microflora comprising L. crispatus as a member (n $=83$ ) rarely shifted away from grade I VMF microflora $(2.4 \%)$. Such a shift was observed on merely two occasions (shift to grade I-like and grade II VMF respectively) and was not associated with the disappearance of $L$. crispatus (Table 5). Normal microflora comprising L. jensenii as a member $(n=42)$ shifted away from grade I VMF microflora on three occasions (on each occasion involving a grade Ib VMF to grade II VMF transition) (7.2\%), and on two occasions this was associated with the loss of L. jensenii (Table 5). Finally, normal VMF comprising L. gasseri/ iners as a member $(\mathrm{n}=83)$ converted to abnormal VMF on twelve occasions (involving conversion from grade I VMF to grade I-like five times, to grade II six times, and to grade III once) (14.5\%) (Table 5), which was associated with the disappearance of $L$. gasseri/iners in merely two out of the twelve normal to abnormal VMF transitions. It may be added that in the aforementioned instances, including the two L. crispatus comprising VMF and the three L. jensenii comprising VMF which converted to abnormal VMF, $L$. gasseri/iners was actually present alongside L. crispatus respectively $L$. jensenii. So, in summary conversion from normal VMF to abnormal VMF was associated twice with grade I L. crispatus + L. gasseri/iners microflora, three times with grade I L. jensenii + L. gasseri/iners microbiota, and seven times with grade I microbiota only containing $L$. gasseri/iners. In one additional case, conversion from normal VMF to abnormal VMF occurred with a woman with grade Ib VMF from which no lactobacilli could be identified through tRFLP and culture.

\section{Summary of the association between normal microflora type and vaginal microflora status on follow-up}

Overall, in this cohort, normal VMF at baseline examination shifted to an abnormal VMF on follow-up at a rate of $16.9 \%$, whereby - according to Gram stain - $92.3 \%$ of these cases were associated with a departure from grade Ib VMF and - according to tRFLP and culture - $92.3 \%$ of these cases involved a departure from grade I VMF comprising L. gasseri/iners. Conversely, the presence of $L$. crispatus even when accompanied by the other Lactobacillus species, L. jensenii, L. gasseri and/or L. iners, emerged as a prominent stabilising factor to the vaginal microflora. In particular, normal VMF comprising L. gasseri/iners incurred a ten-fold increased risk of conversion to abnormal VMF relative to non-L. gasseri/iners VMF (RR 10.41, 95\% CI 1.39-78.12, $\mathrm{p}=0.008$ ), whereas normal VMF comprising L. crispatus had a five-fold decreased risk of conversion to abnormal VMF relative to non- $L$. crispatus VMF (RR 0.20, 95\% CI 0.05-0.89, p = 0.04).

Of importance is that, while on the one hand it was observed that L. jensenii and L. gasseri/iners tended to disappear at a significantly higher rate over time (i.e. displaying poorer colonisation strength) as compared to $L$. crispatus, and on the other hand that L. jensenii and in particular L. gasseri/iners were associated with a much higher risk of conversion from normal to abnormal VMF (i.e. displaying poorer colonisation resistance), these phenomena did not seem to be interrelated, i.e. conversion to abnormal VMF is mostly accompanied by the persistence rather than the disappearance of the Lactobacillus index species. Hence, it appears as if L. jensenii and L. gasseri/iners in particular, elicit in comparison to L. crispatus both poorer colonisation strength and poorer colonisation resistance. 


\section{Longitudinal analysis of the prevalence of Lactobacillus species according to culture and tRFLP with advancing pregnancy}

Finally, we examined the trends in the occurrence of the distinct Lactobacillus species as indentified through culture and tRFLP with advancing pregnancy. When accounting for the subsequent trimesters $L$. crispatus was present in 42,49 , and 60 of the 100 women respectively, L. jensenii in 27, 33, and 32 patients, and L. gasseri/iners in 59, 57, and 49 subjects, respectively. Accordingly, there was a significant positive trend in the occurrence of L. crispatus $\left(\chi^{2}\right.$ test-for-trend $=6.46, \mathrm{p}=0.011)$, while there was no significant trend in the prevalence of $L$. jensenii ( $\chi^{2}$ test-for-trend $=0.59, \mathrm{p}=0.4)$, nor in the occurrence of L. gasseri/iners $\left(\chi^{2}\right.$ test-for-trend $=2.01, \mathrm{p}=0.2)$. Hence a significant increase in the presence of $L$. crispatus with grade I VMF (prevalence ratio $1.32,95 \% \mathrm{CI} 1.01-1.72, \mathrm{p}=0.04$ ) from the first to the third trimester was observed, whereas conversely there was a trend towards a decreased presence of L. gasseri/iners with grade I VMF (prevalence ratio 0.77, 95\% CI 0.56 $1.06, \mathrm{p}=0.1$ ), albeit non-significant. Consequently while there was no significant trend in the prevalence of normal VMF with advancing pregnancy in this cohort, a larger number of women with normal VMF gained $L$. crispatus.

\section{Discussion}

The vaginal lactobacilli were originally described in the late $19^{\text {th }}$ century by German gynaecologist Albert Döderlein, who purported that the lactobacilli act as a barrier of defence preventing other bacteria to ascend the genital tract [19]. Since then, it has been established that the vaginal lactobacilli are indeed capable of providing colonisation resistance through a variety of mechanisms. Nonetheless, failure of the lactobacilli-driven defence often occurs, resulting in overgrowth of the vaginal epithelium by other bacteria, as observed, most typically, with anaerobic polymicrobial overgrowth in bacterial vaginosis and less commonly with overgrowth by bifidobacteria $[7,8]$ and other bacteria.

From this perspective, major interest in the study of the vaginal lactobacilli has emerged in recent years, as it is assumed that thorough characterisation of the normal vaginal microflora may provide us with a better understanding of the mechanisms involved with the stability of lactobacilli-dominated microflora, or conversely, with their failure to maintain the vaginal ecosystem. It was recently established that of the 80 known Lactobacillus species, up to 20 different species may colonize the intestinal tract, yet merely four species seem to dominate the vaginal microflora, in particular L. crispatus, L. jensenii, L. gasseri and $L$. iners $[7,17,18]$, a finding that has now been corroborated in various parts of the world among women with differing ethnicity[20], albeit a fifth species L. vaginalis may have been overlooked by culture-independent methods (unpublished data). Based on the distinctive mor-
Table 3: Composition of grade I microbiota according to culture and tRFLP in the first pregnancy trimester $(n=77)$

\begin{tabular}{lc}
\hline L. crispatus (only) & $23.4 \%($ I8) \\
L. jensenii (only) & $3.9 \%(3)$ \\
L. gasseri/L. iners (only) & $40.3 \%(3 \mathrm{I})$ \\
& \\
L. crispatus + L. jensenii & $15.6 \%(I 2)$ \\
L. crispatus + L. gasseri/L. iners & $9.1 \%(7)$ \\
L. jensenii + L. gasseri/L. iners & $3.9 \%(3)$ \\
L. crispatus + L. jensenii + L. gasseri/L. iners & $2.6 \%(2)$ \\
& \\
unidentified & $1.3 \%(I)$ \\
\hline
\end{tabular}

phology of the Lactobacillus index species, we previously showed that it is possible to differentiate between various types of normal or grade I vaginal microflora, in particular grade Ia when only Lactobacillus crispatus cell types (plump, mostly short rods) are present, grade Ib when only other Lactobacillus cell types are present (smaller or more elongated and less stained than in Ia smears) and as grade Iab when both $L$. crispatus and other lactobacilli are present [7].

In the present study it could be shown that of all women who presented with normal or grade I VMF during the first trimester and who converted to abnormal VMF in the second or third trimester, the shift from normal to abnormal $\mathrm{VMF}$ was for the most part preceded by the presence of grade Ib VMF, whereas grade Ia and Iab VMF rarely shifted away to an abnormal VMF. We further explored whether this finding translated to the Lactobacillus species level through culture and tRFLP fingerprinting. It could be shown that grade I VMF comprising L. crispatus shifted away to abnormal VMF in merely $2.4 \%$ of the cases, whereas grade I VMF containing L. gasseri/iners converted to abnormal VMF at a rate of $14.5 \%$ of the cases respectively. Accordingly, normal VMF comprising L. gasseri/ iners incurred a ten-fold increased risk of conversion to abnormal VMF relative to non- $L$. gasseri/iners VMF (RR $10.41,95 \%$ CI 1.39-78.12, $\mathrm{p}=0.008$ ), whereas normal VMF comprising $L$. crispatus had a five-fold decreased risk of conversion to abnormal VMF relative to non-L. crispatus VMF (RR 0.20, 95\% CI 0.05-0.89, $\mathrm{p}=0.04$ ).

The observation that $L$. gasseri/iners comprising VMF apparently offers significantly less stability as compared to L. crispatus containing VMF, was not explained however by the higher rate at which $L$. gasseri/iners disappeared on follow-up, or hence by their lower colonisation strength. Rather it appears as if $L$. gasseri and L. iners offer poorer colonisation resistance thereby allowing the overgrowth of other bacteria. This finding concurs at least in part with what we recently reported, i.e., contrary to the traditional contention that the progression of normal over intermediate to bacterial vaginosis VMF involves the disappearance of the vaginal lactobacilli, we showed that $L$. gasseri prolif- 
Table 4: Overview of the prevalence of the Lactobacillus index species at three consecutive points in time during pregnancy for the 77 women with grade I microflora during the first trimester

\begin{tabular}{|c|c|c|c|}
\hline \multicolumn{4}{|c|}{ Lactobacillus species as determined through culture and tRFLP $(\mathrm{N}=77)$} \\
\hline & $\begin{array}{l}\text { trimester I } \\
\text { (n) }\end{array}$ & $\begin{array}{l}\text { trimester II } \\
\text { (n) }\end{array}$ & $\begin{array}{l}\text { trimester III } \\
\text { (n) }\end{array}$ \\
\hline all samples with an $L$. crispatus TRF & $\begin{array}{c}39 \\
(100 \%)\end{array}$ & $\begin{array}{c}37 \\
(94.9 \%)\end{array}$ & $\begin{array}{c}36 \\
(92.3 \%)\end{array}$ \\
\hline all samples with an $L$. jensenii TRF & $\begin{array}{c}20 \\
(100 \%)\end{array}$ & $\begin{array}{c}18 \\
(90.0 \%)\end{array}$ & $\begin{array}{c}16 \\
(80.0 \%)\end{array}$ \\
\hline all samples with an L. gasseriliners TRF & $\begin{array}{c}43 \\
(100 \%)\end{array}$ & $\begin{array}{c}36 \\
(83.7 \%)\end{array}$ & $\begin{array}{c}30 \\
(69.8 \%)\end{array}$ \\
\hline
\end{tabular}

erates with intermediate VMF and that $L$. iners growth is enhanced with bacterial vaginosis [21].

Hence, from the present study on the natural history of the normal vaginal microflora in pregnant women, it appears that $L$. crispatus, is associated with a particularly stable vaginal ecosystem. Conversely, microflora comprising L. jensenii elicits intermediate stability, while VMF comprising L. gasseri/L. iners is the least stable.

Interestingly, Kalra et al recently suggested that bacterial vaginosis might arise selectively from subtypes of normal microflora and that recolonisation with $L$. iners following an episode of bacterial vaginosis might be a risk factor for recurrence [22]. Ferris et al analysed the vaginal microflora among six patients treated with $0.75 \%$ topical metronidazole gel applied once daily for five days and found at 30 days posttreatment that a single species, L. iners, was predominant in all patients, except for the one patient for whom treatment failed both according to Nugent and Amsel criteria [23]. Hence, it has been suggested that following the resolution of bacterial vaginosis, $L$. iners is the only Lactobacillus species that succeeds to replenish the vagina in appreciable amounts, which in turn may render these patients more vulnerable to a new episode of bacterial vaginosis, considering the rather moderate colonisa-

Table 5: Association between Lactobacillus type as part of grade I microflora (on culture and tRFLP) and microflora status (on Gram stain) on follow-up when accounting for the first-to-second and second-to-third trimester transitions

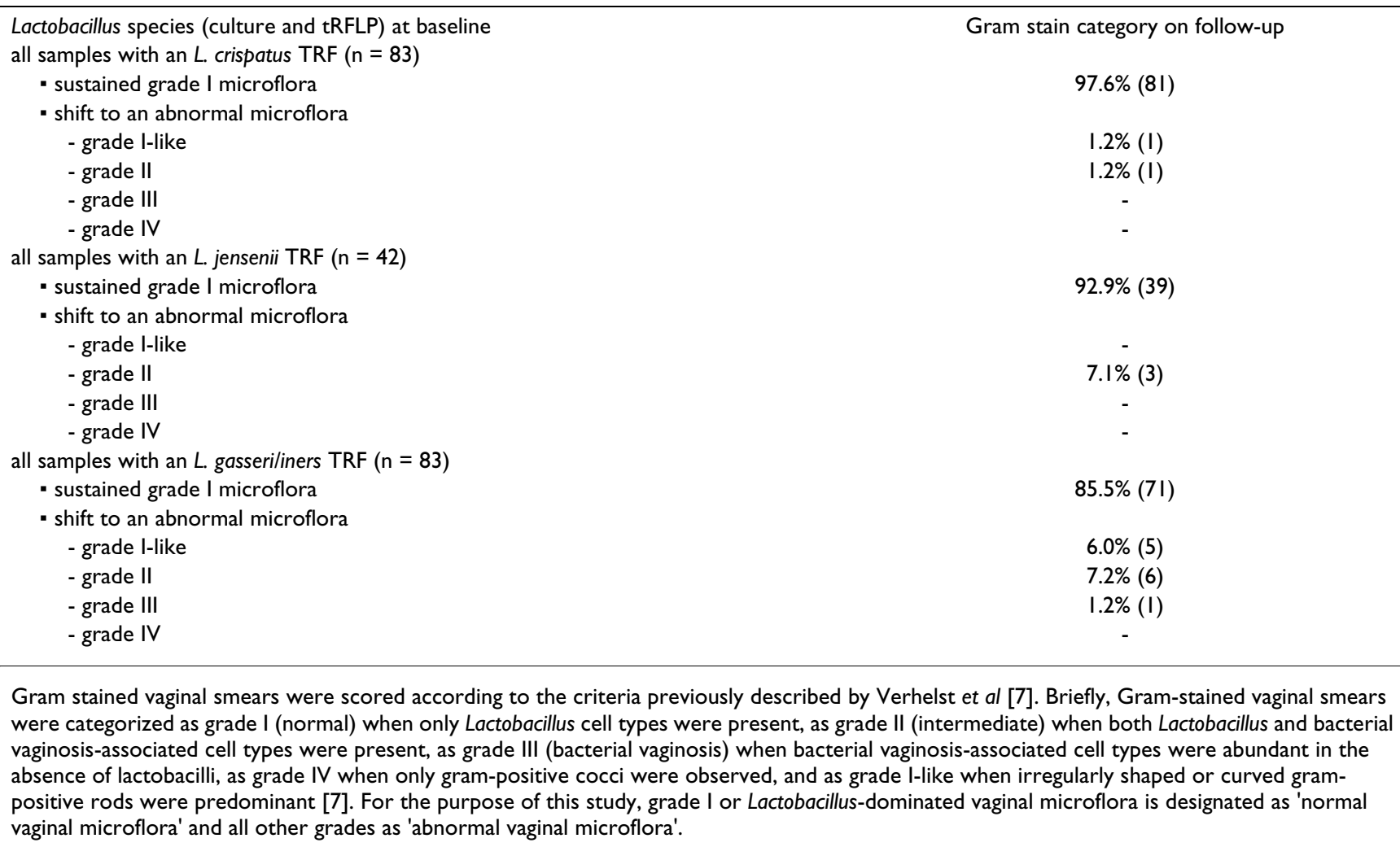

Gram stain category on follow-up

Gram stained vaginal smears were scored according to the criteria previously described by Verhelst et al [7]. Briefly, Gram-stained vaginal smears were categorized as grade I (normal) when only Lactobacillus cell types were present, as grade II (intermediate) when both Lactobacillus and bacterial vaginosis-associated cell types were present, as grade III (bacterial vaginosis) when bacterial vaginosis-associated cell types were abundant in the absence of lactobacilli, as grade IV when only gram-positive cocci were observed, and as grade I-like when irregularly shaped or curved grampositive rods were predominant [7]. For the purpose of this study, grade I or Lactobacillus-dominated vaginal microflora is designated as 'normal vaginal microflora' and all other grades as 'abnormal vaginal microflora'. 
tion resistance offered by L. iners [22]. Jakobsson and Forsum corroborated the finding by Ferris et al and further suggested that $L$. iners may become a dominant part of the vaginal microflora when the microflora is in a transitional stage between abnormal and normal [24].

As our study was confined to genotypic characterisation of the microflora, it remains to be determined which phenotypic attributes of the different Lactobacillus species explain the observed associations. Previous studies have pointed at an important role for hydrogen peroxide production in colonization resistance [25-27]. In a 2 -year follow-up study, Hawes et al documented that the acquisition of bacterial vaginosis was strongly associated with a lack or loss of hydrogen peroxide producing lactobacilli [28]. At first sight, our findings corroborate this paradigm, as most L. crispatus strains have been found to be very consistently strong $\mathrm{H}_{2} \mathrm{O}_{2}$ producers [29,30], whereas most $L$. iners strains have been found to be for the most part non- $\mathrm{H}_{2} \mathrm{O}_{2}$ producers $[29,30]$. However, other factors must be involved as well. In particular, most $L$. jensenii strains have been found to be equally strong $\mathrm{H}_{2} \mathrm{O}_{2}$ producers as $L$. crispatus $[29,30]$, although in this study $L$. jensenii showed a stronger association with conversion to abnormal VMF. A possible explanation is that L. jensenii is the only Lactobacillus species for which poorer colonisation resistance seemed to be correlated with poorer colonisation strength, i.e. conversion to abnormal VMF was more likely to be associated with the disappearance of $L$. jensenii. Compared to the other Lactobacillus species, $L$. jensenii is also on average present in a significantly lower concentration with grade I VMF [21].

Our results must be taken with extreme caution as our study had several important limitations. Firstly, our sample size was rather small and therefore our results need to be corroborated in larger cohorts. Secondly, we acknowledge that the interval between subsequent sampling occasions was rather large with an average of some 3 months interval time. Thirdly, it must be acknowledged that a single sampling occasion may not properly reflect the vaginal microflora status of a woman due to swift changes in the microflora as has been documented previously [31,32]. Fourthly, due to the choice of the BstUI restriction enzyme, which generates equal-sized terminal fragment lengths for $L$. gasseri and L. iners on TRFLP, we were unable to differentiate between $L$. gasseri and L. iners, also because we failed to culture these species consistently. Previous studies have applied tRFLP more successfully in this respect $[33,34]$. Fifthly, it must be acknowledged that we did not record any behavioural factors that might have impinged on vaginal microflora status during the study. Though not necessarily confounding our results, this might have been most informative. Finally, as the study was conducted among pregnant women our results may not be representative for the natural history of the vaginal microflora among non-pregnant women.

\section{Conclusion}

In conclusion, we believe to have documented that the presence of different Lactobacillus species with the normal vaginal microflora (VMF) is a major determinant to the stability of the VMF in pregnancy. The presence of $L$. crispatus seems to ensure ongoing presence of $L$. crispatus and normal VMF; the presence of $L$. jensenii is associated with normal VMF, but L. jensenii is more likely to disappear over time which may lead to overgrowth by other bacteria; the presence of $L$. gasseri/L. iners is likely to vary over time and strongly predisposes to bacterial overgrowth of the vagina in pregnancy. These observations are paramount in view of the vast disease burden associated with depleted lactobacilli and bacterial vaginosis in particular, a condition that affects at any time some 10 to $50 \%$ of women worldwide [35]. As a matter of fact, the whole point of it is that these observations appear to challenge the century-old paradigm of "normal" or "healthy" vaginal microflora, a state that is still defined by the enumeration of bacterial cell morphotypes on microscopy. In particular, as we found that some half of women actually have a microflora characterized by the poorer colonizers and defenders L. gasseri and L. iners, it may be inferred that in a substantial proportion of women lactobacilli-driven antimicrobial defence of the lower female genital tract is actually less optimal than can be assumed by the mere presence of lactobacilli.

\section{Methods Study Population}

In a prospective cohort study, unselected pregnant women were consecutively enrolled through informed consent on the occasion of their first antenatal visit, from January 2003 through May 2004, at the outpatient obstetric clinic of the Ghent University Hospital [8]. Patients were scheduled to provide three vaginal swabs at three points in time corresponding to subsequent pregnancy trimesters. The first 100 women with complete series of swabs were considered for longitudinal analysis of the normal vaginal microflora.

\section{Clinical procedures}

A cotton-tipped wooden vaginal swab (Euron, Ontex, Belgium) was rolled against the lateral vaginal walls, carefully withdrawn, and rolled out on a plain glass slide; the airdried vaginal smear was then Gram-stained. A second, sterile cotton-tipped wooden swab (Sterilin, Copan, Italy) was rolled against the lateral vaginal walls and placed in a sterile polypropylene tube for transport. A third swab was obtained in a similar manner and placed into Amies transport medium (Nuova Aptaca, Canelli, Italy) for anaerobic culture. 


\section{Grading of Gram-stained vaginal smears}

The Gram stained vaginal smears were scored by two independent assessors (GC and RV) according to the criteria previously described by Verhelst et al [7]. Briefly, Gramstained vaginal smears were categorized as grade I (normal) when only Lactobacillus cell types were present, as grade II (intermediate) when both Lactobacillus and bacterial vaginosis-associated cell types were present, as grade III (bacterial vaginosis) when bacterial vaginosis-associated cell types were abundant in the absence of lactobacilli, as grade IV when only gram-positive cocci were observed, and as grade I-like when irregularly shaped or curved gram-positive rods were predominant [7]. For the purpose of this study, grade I or Lactobacillus-dominated vaginal microflora is designated as 'normal vaginal microflora' and all other grades as 'abnormal vaginal microflora'.

\section{Culture and identification of cultured isolates by tDNA- PCR}

The swab on Amies transport medium was streaked onto Schaedler agar enriched with 5\% sheep blood, vitamin $\mathrm{K}$, haemin and sodium pyruvate (Becton Dickinson, Franklin Lakes, NJ) and incubated anaerobically at $37^{\circ} \mathrm{C}$ upon arrival at the microbiology laboratory. After 4 days of incubation, all the isolates with different colony morphology were selected for identification. DNA was extracted by simple alkaline lysis: one colony was suspended in $20 \mu \mathrm{l}$ of $0.25 \%$ sodium dodecyl sulfate- $0.05 \mathrm{~N} \mathrm{NaOH}$, heated at $95^{\circ} \mathrm{C}$ for $15 \mathrm{~min}$ and diluted with $180 \mu \mathrm{l}$ of distilled water. tDNA-PCR and capillary electrophoresis were carried out as described previously [36,37]. The species to which each isolate belonged was determined by comparing the tDNA-PCR fingerprint obtained from each isolate with a library of tDNA-PCR fingerprints obtained from reference strains, using an in-house software program [37]. The library of tDNA-PCR fingerprints is available at our website and the software can be obtained upon request [38].

\section{DNA extraction of vaginal swab samples}

For DNA extraction from the dry vaginal swabs, the QIAamp DNA mini kit (Qiagen, Hilden, Germany) was used according to the manufacturer's recommendations, with minor modifications. The dry swab specimen from each patient was swirled for $15 \mathrm{~s}$ in $400 \mu \mathrm{l}$ of lysis buffer (20 mM Tris-HCl, pH 8.0; 2 mM EDTA; 1.2\% Triton). Fifty units of mutanolysin $(25 \mathrm{U} / \mu \mathrm{l}$ ) (Sigma, Bornem, Belgium) were added and the samples were incubated for 30 min at $37^{\circ} \mathrm{C}$. After the addition of $20 \mu$ l Proteinase K (20 $\mathrm{mg} / \mathrm{ml}$ ) and $200 \mu \mathrm{l} \mathrm{AL}$ buffer (Qiagen), samples were incubated for $30 \mathrm{~min}$ at $56^{\circ} \mathrm{C}$. Next, $200 \mu \mathrm{l}$ of ethanol was added and DNA was purified by adding the lysate to the Qiagen columns as described by the manufacturer. Finally, the total bacterial DNA was eluted with $100 \mu \mathrm{l}$ of
AE buffer (Qiagen). DNA extracts were stored at $-20^{\circ} \mathrm{C}$ and were used for the purpose of T-RFLP analysis and species specific PCR.

\section{tRFLP analysis}

The forward primers 10f (5' TET-AGTTTGATCCTGGCTCAG) or GV10f (5' TET-GGTTCGATTCTGGCTCAG) and the reverse primer 534r (5' ATTACCGCGGCTGCTGG) $[7,33]$ which target the $16 \mathrm{~S}$ rRNA gene of the domain Bacteria, were used to amplify part of the $16 \mathrm{~S}$ rDNA by PCR. Two $15 \mu$ PCR mixtures contained respectively primer set $10 f-534 \mathrm{r}$ or GV10f-534r at a final concentration of $0.1 \mu \mathrm{M}$ of each primer and at a ratio of labelled and unlabelled forward primer of 2/3, $7.5 \mu \mathrm{l}$ of Promega master mix (Promega, Madison, WI) $1.5 \mu \mathrm{l}$ of sample and $5.9 \mu \mathrm{l}$ HPLC water. Thermal cycling consisted of an initial denaturation of $5 \mathrm{~min}$ at $94^{\circ} \mathrm{C}$, followed by three cycles of 1 min at $94^{\circ} \mathrm{C}, 2 \mathrm{~min}$ at $50^{\circ} \mathrm{C}$ and $1 \mathrm{~min}$ at $72^{\circ} \mathrm{C}$, followed by 35 cycles of $20 \mathrm{sec}$ at $94^{\circ} \mathrm{C}, 1 \mathrm{~min}$ at $50^{\circ} \mathrm{C}$ and $1 \mathrm{~min}$ $72^{\circ} \mathrm{C}$, with a final extension of $10 \mathrm{~min}$ at $72^{\circ} \mathrm{C}$, and cooling to $10^{\circ} \mathrm{C}$. A $20 \mu \mathrm{l}$ restriction mixture, containing $0.5 \mu \mathrm{l}$ of both PCR-products, $1 \mu \mathrm{l}$ of BstUI (Westburg, Leiden, The Netherlands), $4 \mu$ l of the appropriate buffer and $14 \mu \mathrm{l}$ milliQ water (Millipore, Bellerica, MA, USA), was incubated at $60^{\circ} \mathrm{C}$ during $3 \mathrm{~h}$. Five $\mu \mathrm{L}$ of the restriction reaction was purified by ethanol precipitation. The obtained pellet was resolved in $13.1 \mu \mathrm{l}$ deionised formamide (AMRESCO, Solon, Ohio), $0.1 \mu \mathrm{l}$ ROX500 and $0.3 \mu \mathrm{l}$ HD400 GeneScan size standards (Applied Biosystems, Foster City, CA) followed by denaturation at $96^{\circ} \mathrm{C}$ for 2 min and immediate cooling on ice. The restriction fragments were electrophoresed on an ABI PRISM 310 (Applied Biosystems), whereby only the fluorescently labelled 5' terminal restriction fragments (TRFs) were visualized.

The T-RFLP pattern obtained from a sample with a mixed microflora consists of one TRF for each of the different species present. Theoretically the number of peaks (TRFs) reflects the number of different species present in a sample. Identification of the peaks in a T-RFLP pattern, in other words assignation of a species name to each TRF, is based on comparison with a library composed of TRFs that have been obtained from pure cultures of well-identified reference strains or pure $16 \mathrm{~S}$ rDNA clones, identified by sequence determination. The TRF length of a single species can also be determined by carrying out computer assisted (i.e. virtual) restriction analysis of published $16 \mathrm{~S}$ rRNA sequences. The peak values in the library entries are the averages of the peak values obtained after testing different strains or cloned 16S rRNA genes of each species.

The choice of the restriction enzyme used is important. We chose BstUI, based on in silico analysis of $16 \mathrm{~S}$ rRNA genes [39] and on literature [40], indicating that this 
restriction enzyme was well suited for maximal differentiation between Lactobacillus species based on the length of the terminal 5' restriction fragment of their 16S rDNA, i.e. their TRF.

T-RFLP patterns were obtained as table files from the Genescan Analysis software and were analyzed using BaseHopper, a software program developed at our university [36]. Using these sample files containing TRF lengths (peak values) in base pairs, this program enabled us to assign a species name to each TRF by comparing each TRF of a T-RFLP fingerprint separately with the library. TRFs with a peak height of less than $10 \%$ of the highest peak were excluded from the analysis, since such peaks rarely corresponded with any of the species shown to be present by cloning [41].

\section{Statistical analysis}

To compare rates of occurrence of events, ordinary risk ratios with $95 \%$ confidence intervals were calculated, except for paired data, in case of which we calculated McNemar odds ratios with $95 \%$ confidence intervals. Statistical significance was accepted at the two-tailed $\alpha=0.05$ significance level. All analyses were performed with the statistical software package SPSS version 15.0 (SPSS, Chicago, Illinois).

\section{Authors' contributions}

HV and MT participated in the development of the study design, the collection of the study samples, the collection, analysis and interpretation of the data, and in the writing of the report. RV, GC, EDB and MV participated in the development of the study design, the analysis of the study samples, the collection, analysis and interpretation of the data, and in the writing of the report. All authors read and approved the final manuscript.

\section{Acknowledgements}

This study was funded by the Marguerite-Marie Delacroix Foundation, the Special Research Fund (BOF) of the Ghent University, and the Fund for Scientific Research Flanders (Belgium). The Marguerite-Marie Delacroix Foundation, the Special Research Fund (BOF) of the Ghent University, and the Fund for Scientific Research Flanders (Belgium) were not involved in the development of the study design, the collection, analysis, and interpretation of the data, in the writing of the report nor in the decision to submit the paper for publication.

\section{References}

I. Sobel JD: Bacterial vaginosis. Annu Rev Med 2000, 5 I:349-56.

2. Schwebke JR: Gynecologic consequences of bacterial vaginosis. Obstet Gynecol Clin North Am 2003, 30:685-94.

3. Boris $S$, Barbés $C$ : Role played by lactobacilli in controlling the population of vaginal pathogens. Microbes Infect 2000, 2:543-6.

4. Sobel JD, Funaro D, Kaplan EL: Recurrent group A streptococcal vulvovaginitis in adult women: family epidemiology. Clin Infect Dis 2007, 44:e43-5.

5. Sobel JD: Desquamative inflammatory vaginitis: a new subgroup of purulent vaginitis responsive to topical $2 \%$ clindamycin therapy. Am J Obstet Gynecol 1994, 171:1215-20.
6. Donders GG, Vereecken A, Bosmans E, Dekeersmaecker A, Salembier G, Spitz B: Definition of a type of abnormal vaginal flora that is distinct from bacterial vaginosis: aerobic vaginitis. BJOG 2002, 109:34-43.

7. Verhelst R, Verstraelen H, Claeys G, Verschraegen G, Van Simaey L, De Ganck C, De Backer E, Temmerman M, Vaneechoutte M: Comparison between Gram stain and culture for the characterization of vaginal microflora: definition of a distinct grade that resembles grade I microflora and revised categorization of grade I microflora. BMC Microbiol 2005, 5:6I.

8. Verstraelen $H$, Verhelst $R$, Roelens K, Claeys G, Weyers S, De Backer E, Vaneechoutte M, Temmerman M: Modified classification of Gram-stained vaginal smears to predict spontaneous preterm birth: a prospective cohort study. Am J Obstet Gynecol 2007, 196:el-6.

9. Carey JC, Klebanoff MA: Is a change in the vaginal flora associated with an increased risk of preterm birth? Am J Obstet Gynecol 2005, 192:|34|-6.

10. Martin HL, Richardson BA, Nyange PM, Lavreys L, Hillier SL, Chohan B, Mandaliya K, Ndinya-Achola JO, Bwayo J, Kreiss J: Vaginal lactobacilli, microbial flora, and risk of human immunodeficiency virus type $I$ and sexually transmitted disease acquisition. J Infect Dis 1999, 180:1863-8.

II. Wiesenfeld HC, Hillier SL, Krohn MA, Landers DV, Sweet RL: Bacterial vaginosis is a strong predictor of Neisseria gonorrhoeae and Chlamydia trachomatis infection. Clin Infect Dis 2003, 36:663-8

12. Spear GT, St John E, Zariffard MR: Bacterial vaginosis and human immunodeficiency virus infection. AIDS Res Ther 2007, 4:25.

13. Atashili J, Poole C, Ndumbe PM, Adimora AA, Smith JS: Bacterial vaginosis and HIV acquisition: a meta-analysis of published studies. AIDS 2008, 22:1493-50I.

14. Hay P: Life in the littoral zone: lactobacilli losing the plot. Sex Transm Infect 2005, 81: 100-2.

15. Fethers KA, Fairley CK, Hocking JS, Gurrin LC, Bradshaw CS: Sexual risk factors and bacterial vaginosis: a systematic review and meta-analysis. Clin Infect Dis 2008, 47:| 1426-35.

16. Brotman RM, Klebanoff MA, Nansel TR, Andrews WW, Schwebke JR, Zhang J, Yu KF, Zenilman JM, Scharfstein DO: A longitudinal study of vaginal douching and bacterial vaginosis - a marginal structural modeling analysis. Am J Epidemiol 2008, 168:188-96.

17. Vásquez A, Jakobsson T, Ahrné S, Forsum U, Molin G: Vaginal lactobacillus flora of healthy Swedish women. J Clin Microbiol 2002, 40:2746-9.

18. Fredricks DN, Fiedler TL, Marrazzo JM: Molecular identification of bacteria associated with bacterial vaginosis. $N$ Engl J Med 2005, 353:1899-9|1.

19. Döderlein A: Das Scheidensekret und seine Bedeutung für das Puerperalfieber. Verlag Eduard Besold, Leipzig 1892.

20. Reid G: Lactobacillus in the Vagina: Why, How, Which Ones and What Do They Do? In Lactobacillus Molecular Microbiology: From Genomics to Probiotics Edited by: Ljungh A, Wadström T. Norfolk: Caister Academic Press; 2009.

21. De Backer E, Verhelst R, Verstraelen H, Alqumber MA, Burton JP, Tagg JR, Temmerman M, Vaneechoutte M: Quantitative determination by real-time PCR of four vaginal Lactobacillus species, Gardnerella vaginalis and Atopobium vaginae indicates an inverse relationship between $L$. gasseri and $L$. iners. BMC Microbiol 2007, 7:115.

22. Kalra A, Palcu CT, Sobel JD, Akins RA: Bacterial Vaginosis: Culture- and PCR-based Characterizations of a Complex Polymicrobial Disease's Pathobiology. Curr Infect Dis Rep 2007, 9:485-500.

23. Ferris MJ, Norori J, Zozaya-Hinchliffe M, Martin DH: Cultivationindependent analysis of changes in bacterial vaginosis flora following metronidazole treatment. J Clin Microbiol 2007, 45: $1016-8$

24. Jakobsson T, Forsum U: Lactobacillus iners: a marker of changes in the vaginal flora? J Clin Microbiol 2007, 45:3।45.

25. Eschenbach DA, Davick PR, Williams BL, Klebanoff SJ, Young-Smith $\mathrm{K}$, Critchlow CM, Holmes KK: Prevalence of hydrogen peroxide-producing Lactobacillus species in normal women and women with bacterial vaginosis. J Clin Microbiol 1989, 27:25I-6.

26. Hillier SL, Krohn MA, Klebanoff SJ, Eschenbach DA: The relationship of hydrogen peroxide-producing lactobacilli to bacterial 
vaginosis and genital microflora in pregnant women. Obstet Gynecol 1992, 79:369-73.

27. Hillier SL, Krohn MA, Rabe LK, Klebanoff SJ, Eschenbach DA: The normal vaginal flora, $\mathrm{H2O}$ 2-producing lactobacilli, and bacterial vaginosis in pregnant women. Clin Infect Dis 1993, 16:S273-81.

28. Hawes SE, Hillier SL, Benedetti J, Stevens CE, Koutsky LA, WolnerHanssen P, Holmes KK: Hydrogen peroxide-producing lactobacilli and acquisition of vaginal infections. J Infect Dis 1996 174: 1058-63.

29. Antonio MA, Hawes SE, Hillier SL: The identification of vaginal Lactobacillus species and the demographic and microbiologic characteristics of women colonized by these species. J Infect Dis 1999, 180:1950-6.

30. Antonio MA, Rabe LK, Hillier SL: Colonization of the rectum by Lactobacillus species and decreased risk of bacterial vaginosis. J Infect Dis 2005, 192:394-8.

31. Priestley C], Jones BM, Dhar J, Goodwin L: What is normal vaginal flora? Genitourin Med 1997, 73:23-8.

32. Schwebke JR, Morgan SC, Weiss HL: The use of sequential selfobtained vaginal smears for detecting changes in the vaginal flora. Sex Transm Dis 1997, 24:236-9.

33. Zhou X, Brown CJ, Abdo Z, Davis CC, Hansmann MA, Joyce P, Foster JA, Forney LJ: Differences in the composition of vaginal microbial communities found in healthy Caucasian and black women. ISME J 2007, I: | 2 |-33.

34. Thies FL, König W, König B: Rapid characterization of the normal and disturbed vaginal microbiota by application of $16 \mathrm{~S}$ rRNA gene terminal RFLP fingerprinting. J Med Microbiol 2007, 56:755-6I.

35. Koumans EH, Sternberg M, Bruce C, McQuillan G, Kendrick J, Sutton $M$, Markowitz LE: The prevalence of bacterial vaginosis in the United States, 200I-2004; associations with symptoms, sexual behaviors, and reproductive health. Sex Transm Dis 2007 34:864-9.

36. Baele M, Baele P, Vaneechoutte M, Storms V, Butaye P, Devriese LA, Verschraegen G, Gillis M, Haesebrouck F: Application of tDNAPCR for the identification of enterococci. J Clin Microbiol 2000, 38:420I-4207.

37. Baele M, Vaneechoutte M, Verhelst R, Vancanneyt M, Devriese LA, Haesebrouck F: Identification of Lactobacillus species using tDNA-PCR. J Microbiol Methods 2002, 50:263-27I.

38. tDNA-PCR Library [http://users.ugent.be/ mvaneech/All C.txt]

39. MICA: Virtual Digest. [http://mica.ibest.uidaho.edu/digest.php].

40. Engebretson J], Moyer CL: Fidelity of select restriction endonucleases in determining microbial diversity by terminalrestriction fragment length polymorphism. Appl Environ Microbiol 2003, 69:4823-9.

4I. Verhelst R, Verstraelen H, Claeys G, Verschraegen G, Delanghe J, Van Simaey L, De Ganck C, Temmerman M, Vaneechoutte M: Cloning of 16S rRNA genes amplified from normal and disturbed vaginal microflora suggests a strong association between Atopobium vaginae, Gardnerella vaginalis and bacterial vaginosis. BMC Microbiol 2004, 4:.
Publish with Bio Med Central and every scientist can read your work free of charge

"BioMed Central will be the most significant development for disseminating the results of biomedical research in our lifetime. "

Sir Paul Nurse, Cancer Research UK

Your research papers will be:

- available free of charge to the entire biomedical community

- peer reviewed and published immediately upon acceptance

- cited in PubMed and archived on PubMed Central

- yours - you keep the copyright
BioMedcentral 